\title{
BMJ Open Home visits in primary care: contents and organisation in daily practice. Study protocol of a cross-sectional study
}

\author{
Karen Voigt, ${ }^{1}$ Stefan Bojanowski, ${ }^{1}$ Stephanie Taché, ${ }^{1,2}$ Roger Voigt, ${ }^{3}$ \\ Antje Bergmann ${ }^{1}$
}

To cite: Voigt $\mathrm{K}$,

Bojanowski S, Taché S, et al. Home visits in primary care: contents and organisation in daily practice. Study protocol of a cross-sectional study. BMJ Open 2016;6:e008209. doi:10.1136/bmjopen-2015008209

- Prepublication history for this paper is available online. To view these files please visit the journal online (http://dx.doi.org/10.1136/ bmjopen-2015-008209).

Received 16 March 2015 Revised 4 November 2015 Accepted 9 November 2015

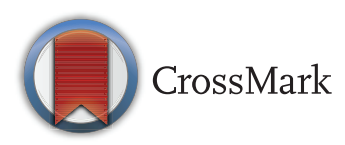

${ }^{1}$ Department of General Practice/Medical Clinic III, Faculty of Medicine,

Technische Universität Dresden, Dresden, Germany ${ }^{2}$ Department of Family and Community Medicine, University California San Francisco,

San Francisco, California, USA

${ }^{3}$ General practitioner in a group practice in Oderwitz/ Saxony, Oderwitz, Germany

Correspondence to Dr Karen Voigt; Karen.Voigt@uniklinikumdresden.de

\section{ABSTRACT}

Introduction: Medical care of homebound patients by home visits is an integral part of primary care in Germany and other industrialised countries. Owing to the sociodemography and changes in the health system, the need for home visits is projected to increase rather than decrease. Our study will provide information on content and organisation of home visits. This evidence is needed to assure sufficient medical care for homebound patients. Germany is one of the European nations with highest proportions of elderly age groups, so that our results will be indicative for other European countries with comparable organisation of primary care.

Methods and analysis: This cross-sectional study is conducted over a period of 12 months. All home visits of each participating family practice are documented within a 1-week time period. The anonymous documentation of home visits is carried out by the family practitioner or medical assistant conducting the home visit. All Saxon Family practitioners received study information and were personally invited to participate in our study. Almost 303 (of 2677) family practitioners expressed their interest to participate to generate data on the content and organisational characteristics of home visits. Data analysis of more than 4000 home visits will take into account several patient-related and system-related parameters. Descriptive and multivariate analysis will be carried out by using non-parametric methods. Regarding expected cluster structure of the data, a multilevel analysis will be necessary.

Ethics and dissemination: The study received ethical approval by the Ethical Commission of the TU Dresden and adheres to the Declaration of Helsinki. Considering that the results of our project will be indicative for ageing societies with comparable organisation of primary care, we will publish them in international open access journals concerned with healthcare and primary care research and disseminate them by a final symposium and at national/international scientific events.

\section{INTRODUCTION}

Medical care of homebound patients by home visits is an integral part of primary care in
Germany as well as other industrialised countries. The organisation of home visits may differ depending on organisation of the primary care system. In primary care systems that are organised into group practices with broad availability of more highly qualified nurses or medical assistants in part with academic degrees, the ability for task sharing, including conducting home visits, is well established (eg, Canada, UK, Finland, USA, Australia). Conversely, primary care systems mostly organised through single practices and without academic or higher qualification of medical assistants such as Belgium, Czech Republic or Germany, home visits continue to be a core task of the family physician (FP). Since all of these countries experience shortages of FPs while needing to maintain or improve access to primary care in the face of increasing prevalence of chronic disorders and multimorbidity, reorganisation of primary care systems is currently being discussed. ${ }^{1-3}$

Besides common demographic changes (growing proportions of the older and very old population) and the parallel rising prevalence of chronic diseases and of multimorbidity in the elderly population ${ }^{4}{ }^{5}$ social changes must also be considered. In Germany, most elderly patients live in private households. In general, the proportions of single and childless households are rising. Based on this, the traditional family support networks are expected to continue weakening in the future. ${ }^{6}$ However, homebound patients are especially dependent on family support or comparable social support networks. With loss of private social support networks, greater external support is required as a general rule. In countries such as Germany or Belgium, where primary care services are not offered by the communities, private (mostly single) family practices remain the most important source of medical care and social support for homebound patients. ${ }^{7}$ 
These patients are often characterised by multimorbidity and advanced age. Previous studies show a positive association between patient age and frequency of home visits and a more frequent utilisation of home visits in age groups $>75$ years. ${ }^{8-10}$ Asides from older patients, other groups of patients also require home visits. These include younger and temporarily immobile patients who cannot visit the family practice during, for example, a serious acute illness. Additionally, there are patients who must receive medical care at home because of, for example, an early hospital discharge. Since 1991, the length of hospitalisations has continuously been reduced in German hospitals. This is due to a variety of factors including new diagnostic and therapeutic procedures, and organisational changes like implementation of settlement based on diagnosis-related groups. ${ }^{11}$ As a result of earlier hospital discharges, a rise in the need for posthospitalisation follow-up care at home by FPs has been reported. ${ }^{12}$

Owing to the demographic and social changes as well as changes in the health system, the need for home visits in Germany and in other comparable countries will increase rather than decrease. In contrast, national and international data show (1) that home visits by primary care practices are decreasing since the past decades ${ }^{9} 13$ and (2) that there is a present or prognosed increase in FP shortages especially in rural regions where the proportion of elderly patients and the emigration of the younger generations are commonly even higher compared to urban regions.

Most of the previously existing research data of German and international studies regarding FPs' home visits are based on secondary analysis of billing data coded by International Statistical Classification of Diseases and Related Health Problems (ICD). ${ }^{8}{ }^{13-16}$ Since ICD codes only include settled diagnosis and do not reflect working contents, the International Classification of Primary Care (ICPC) is the more reliable coding instrument for description of FPs' work contents. Billing data from home visits in Germany only include patient-related ICD codes, information on the visit type (urgent or planned) and the timing of the visit (during or outside consultation hours). There is no clear definition of urgency as part of billing code directives and, it is left up to the FP to decide whether the home visit is urgent or not. ${ }^{17}$ Thus, a primary data study using ICPC is essential to gain more detailed information regarding visit type, reason for visit as well as the organisational aspects of home visits in Germany. In the context of social changes in ageing societies such as Germany, organisation of medical home care must be restructured to assure sufficient medical care for homebound patients especially in rural and other underserved areas. Task sharing models should meet requirements based on reasons for and contents of home visits as well as regional differences in primary care structures.

Our study intends to provide evidence for discussion and decision-making on the organisation of outpatient primary care for patients needing to be cared for in their home. Based on primary data collection, we will generate data regarding content and organisational characteristics of home visits and take several influencing factors into account. With regards to patient characteristics, home visits will be considered in relation to patients' morbidity, living situation and urgency of the reason for the home visit. Regarding external influencing factors, size of the community and FP density/ distribution will be taken into account. The following research questions will be answered:

- What are common reasons and results for encounter in home visits? Are there differences depending on region, housing situation, age and gender?

- Which diagnostic and therapeutic services and decisions are conducted during home visits? How do they differ depending on reasons and results for encounter/patients' morbidity during home visits?

- During which time periods are home visits performed and what time requirement (distance travels and duration of visit) characterise the home visit depending on region? What does this mean for the workload of the FP and the practice staff?

- Who conducts home visits and which tasks are currently delegated to medical assistants and other practice staff? Which tasks are not delegated?

\section{METHODS AND ANALYSIS}

The SESAM-5-study is a cross-sectional survey aiming to collect primary data on the purpose and organisation of FPs' home visits. The study is coordinated by the Department of General Practice of the Technical University of Dresden in cooperation with the Saxonian Association of General Practice (SGAM). This study (SESAM-5) is the fifth part of the SESAM study series (Saxonian Epidemiologic Studies in General Practice) initiated by the SGAM. Study design, recruitment strategies and instruments were tested and improved on by a previous feasibility study. ${ }^{18}$

\section{Study design}

Within this cross-sectional study over a period of 12 months, every participating family practice will document all home visits (in private households as well as in nursing homes) within a 1-week time period. A whole documentation week was selected to meet organisational characteristics of the individual weekly home visit plans. Furthermore, documentation of a week was well accepted by participating general practitioners in our previous feasibility study. ${ }^{18}$ Study period of 12 months was chosen to avoid seasonal biases regarding reasons for encounter.

The documentation of home visits will be carried out by the person (FP or medical assistant) who conducted the home visit. The documentation week was randomised allocated to the family practices. Patient data will be documented anonymously whereas data of FPs and 
medical assistants will be collected pseudonymously caused by the methodic approach.

\section{Recruitment of participants}

Prior to the study recruitment, we advertised in local and German journals that target FPs and in online newsletters, website of the SGAM and at local training events for FPs. We also set up a website (http://www. sesam-studien.de) to provide information concerning the planned study and also regarding previous epidemiological studies and their results.

Using a comprehensive address list of all FPs involved in outpatient primary care in Saxony provided by the Saxonian Association of Statutory Health Insurance Physicians, all registered FPs with a single practice or within a group practice $(\mathrm{n}=2677)$ received in March 2014 a study information and were personally invited by a postal letter to participate in our study. Participation interests could be declared on a prepared reply sheet by fax or email within 4 weeks. A total of 303 FP (11.2\%) expressed their interest to participate and told the closing times of their practices partially (see figure 1).

In consideration of the reported closing times we allocated the documentation week randomly to each FP. We randomised 312 weeks (6 FPs per week within a year) for the 303 FPs using a pseudo random number generator. The nine remaining not allocated weeks were set aside for FPs needing another documentation week (see below).

All FPs were informed about the documentation week and asked to contact us by phone, email or fax if the week does not fit to the practice closing times within the next 2 weeks. After this deadline we allocated in consultation with the FPs new weeks for those who need a new documentation week. Study materials were sent 6 weeks before the documentation week to FPs and their practices. Study material consist of:

- A study information including workflow instructions for the study in general;

- An instruction for handling the documentation sheet for FP and medical assistant that conduct home visits;
- Semistructured documentation sheets;

- Questionnaires about sociodemographic and qualification characteristics of FP and medical assistant as well as;

- Consent sheet for participation for FP and medical assistant.

After 2 or 3 weeks we contacted the family practices personally by phone to ask if material arrived, if there are questions regarding documentation, if there are unexpected cases of being prevented in the allocated week and finally, to keep in contact with the participating FPs. In the week prior the documentation week we phoned again to remind them of the documentation next week. In the ongoing process of delivering of study material and the following phone contacts there were FPs that needed another documentation week (eg, based on staff illness, short-term supply for colleagues, spontaneous vacation, forgotten notes about closing times). In these individual cases we allocated a new week in personal consultation with the FPs. Finally, we changed the documentation week for 74 of 303 (24.4\%) participating FPs. Completed questionnaires and signed consent sheet for participation should be returned in a prepaid envelope. If the material was not returned within 1 month, we reminded for sending it.

\section{Current status of documentation}

The documentation started in July 2014 and was finished in June 2015. We delivered study material to 303 interested FPs. Two hundred and fifty-three of 303 $(83.5 \%)$ practices that documented home visits sent their documentation forms $(n=4255)$ back till end of August. Twenty-one of 303 FPs (6.9\%) dropped out until now because of diseases, death, huge workload by vacation replacement of other practices or no further interest in participating.

\section{Study instruments}

Each home visit in the period of 1 week has to be documented by using a two-side semistructured questionnaire
Figure 1 Flow chart of the study SESAM-5. FP, family physician; SESAM-5, Saxonian Epidemiologic Studies in General Practice.

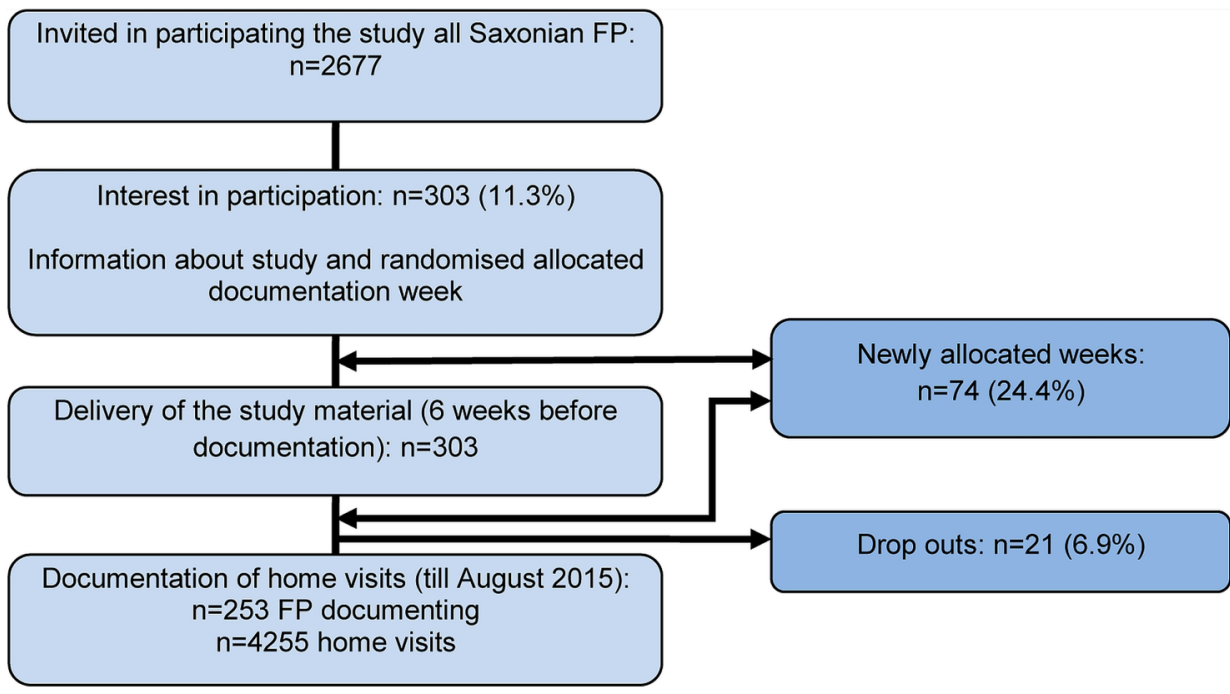


that was tested in the previous feasibility study. ${ }^{18}$ The questionnaire includes closed and open questions regarding organisational features and content of the home visit as well as characteristics of the patient (see table 1). All participating FPs are invited to complete a supplementary questionnaire. This one-side questionnaire included demographic and professional characteristics of the FPs as well as characteristics of the family practice (see table 1/part 2). Medical assistants of family practices that also documented their home visits are asked to complete an additional questionnaire for medical assistants that focus on demographic and professional characteristics as well as description of typical tasks within delegated home visits (see table 1/part 3).

\section{Data analysis}

Representativeness of participating FPs, medical assistants and patients will be examined by external validation using public statistics and comparable scientific articles.

Data of all three questionnaires will be merged in one SPSS matrix. Prior to statistical analysis the documented diagnosis will be coded manually into numeric codification based on International Classification of Diseases 10th Edition (ICD-10), V.2014 by two coders independent of each other. Discrepancies between the codes will be decided by a third person after consulting each coder. Reasons and results for encounter will be coded in the same way using ICPC-2. Answers regarding open-ended variables will be categorised based on contents aiming to integrate common categories in statistical analysis.

Our previous feasibility study showed low missing rates $(<5 \%)$ regarding majority of the questions. ${ }^{18}$ In case of missing data $>10 \%$ we will conduct missing data analysis to examine causes of missing data. Depending on number of missing data and structure of the items we will decide on pairwise deletion or data imputation considering uncertainty of associations between variables as well as reliability of data analysis.

Descriptive analysis will be performed by using non-parametric methods, for example, $\chi^{2}$-test, Kruskal-Wallis-test, Mann-Whitney-U-test to describe data regarding contents of home visits and common reasons and results for encounter depending on several influencing factors (ie, region, housing situation, care level). Time requirements of home visits will be analysed in multivariate regression models integrating multiple influencing factors. Logistic regressions will be conducted to find out predictors for (non-)delegation. Regarding expected cluster structure of the data on different levels of analysis (kind of home visit, housing situation, region), subgroup analysis and multilevel analysis will be necessary.

\section{ETHICS AND DISSEMINATION}

The Ethical Commission granted an amendment allowing collection of data from home visits without patient consent because data collection was anonymised and carried out by FPs or their medical assistants. Drawing conclusion of the measured data on concrete persons is almost impossible.

Considering that the results of our project will be indicative for other ageing societies with comparable organisation of primary care, we will publish our results in international journals concerned with healthcare and primary care research. Publishing is planned preferably in open-access journals to reach a majority of interested recipients. We also plan to publish in German journals to provide our results also for current discussions concerning organisation of primary care and education or training programmes of FPs and medical assistants. Final symposium and presentations at national and international scientific and political events are planned to provide and discuss the main results within the scientific community as well as with decisionmakers of healthcare.

\section{DISCUSSION}

This study will generate data on the content and organisational characteristics of approximately 4000 home visits through 300 FPs distributed over rural and urban regions of a German federal state (Saxony). Saxony is one of the German federal states with the oldest population and Germany one of the European nations with highest proportions of elderly age groups, so that the results of our project will be indicative also for other European countries with comparable organisation of primary care. Based on our expected results, we will discuss possibilities of the future organisation of medical care for homebound patients that will have an impact for countries where home visits are still a core task of the FP. The following questions need to be discussed in the context of ensuring medical care especially in rural regions in the future: Which tasks within home visits could be delegated to whom? Could/should the substitution of home visits to care for chronic patients also be a solution in the context of demographic change and the shortage of family doctors especially in rural underserved regions? How can the use of telemedicine supply requirements to meet? What conditions must be met in order to apply telemedicine or to delegate or substitute home visits? For example, do the medical assistants have the essential professional skills/qualifications and which skills should be further developed and trained?

The results of the study will also have relevance for education or training programmes of FPs and medical assistants. All of these questions focus on answering one main question: how to ensure sufficient primary medical care for homebound patients living in ageing societies especially in rural or underserved regions?

\section{Strengths and limitations of this study}

Methodological issues need to be considered regarding their biasing or confounding effects on the data. Since roughly $11 \%$ of the population of Saxon FPs have 
Table 1 Topics and items of the questionnaires

\begin{tabular}{|c|c|c|c|}
\hline Topics & Items & Item structure & Response options \\
\hline \multicolumn{4}{|c|}{ Questionnaire for documenting home visits } \\
\hline \multirow{5}{*}{$\begin{array}{l}\text { Organisational } \\
\text { characteristics of the home } \\
\text { visits }\end{array}$} & Date, starting time & Single answer & Date and time \\
\hline & Duration of the home visit, driving time & Single answer & In minutes \\
\hline & Person conducting & Multiple choice & FP, medical assistants with/without qualification, physician assistants, other \\
\hline & Urgency of the home visit & & Emergent-very urgent-less urgent-not urgent \\
\hline & Person requesting the home visit & $\begin{array}{l}\text { Single answer/ } \\
\text { checklist }\end{array}$ & $\begin{array}{l}\text { FP, patient, ambulant nursing care, neighbour, relatives, hospital, nursing } \\
\text { home, police/fire department }\end{array}$ \\
\hline \multirow{5}{*}{$\begin{array}{l}\text { Demographic/social } \\
\text { characteristics of the patient }\end{array}$} & Age & Open-ended & Year of birth \\
\hline & Gender & Single answer & Female/male \\
\hline & $\begin{array}{l}\text { Assessment of social support: 'patients seems to } \\
\text { get good social support' }\end{array}$ & Likert scale & $1=$ absolutely true to $6=$ not true \\
\hline & Supporting persons & Multiple choice & $\begin{array}{l}\text { Ambulant nursing care, neighbour, relatives/family, healthcare workers at } \\
\text { nursing home, daycare, no social support, others }\end{array}$ \\
\hline & Domestic circumstances & $\begin{array}{l}\text { Single answer/ } \\
\text { checklist }\end{array}$ & $\begin{array}{l}\text { Living alone at private home, living with partner or family at private home, } \\
\text { assisted living, nursing home }\end{array}$ \\
\hline \multirow[t]{2}{*}{ Disease characteristics } & Known chronic diseases & Open-ended & - \\
\hline & Care level & $\begin{array}{l}\text { Single answer/ } \\
\text { checklist }\end{array}$ & Level 0 to 3 , no or proposed care level, don't know \\
\hline \multirow[t]{5}{*}{ Contents of the home visit } & Reasons and results for encounter & Open-ended & - \\
\hline & Performed diagnostics & Multiple choice & $\begin{array}{l}\text { No diagnostics, comprehensive or symptom-oriented clinical examination, } \\
\text { blood drawing, quick tests, other }\end{array}$ \\
\hline & Therapeutic decision & Multiple choice & $\begin{array}{l}\text { Consultation of patients or relatives or healthcare workers, wound care, } \\
\text { vaccination, prescription of medical and non-medical aids, other }\end{array}$ \\
\hline & Decision & Multiple choice & $\begin{array}{l}\text { Referral to specialist or hospital, home visit for re-evaluation, revisit by FP or } \\
\text { medical assistant, consultation of ambulant nursing care, certificate of } \\
\text { incapacity }\end{array}$ \\
\hline & Drug administration during home visit & Open-ended & Kind of substance and application \\
\hline \multicolumn{4}{|c|}{ Questionnaire for FP and their practices } \\
\hline \multirow{3}{*}{$\begin{array}{l}\text { Demographic/professional } \\
\text { characteristics of the FP }\end{array}$} & Age & Open-ended & Year of birth \\
\hline & Gender & Single answer & Female/male \\
\hline & Kind of employment & $\begin{array}{l}\text { Single answer/ } \\
\text { checklist }\end{array}$ & Resident, full-time or part-time employed, other \\
\hline \multirow[t]{7}{*}{$\begin{array}{l}\text { Characteristics of the family } \\
\text { practice }\end{array}$} & Kind of practice & $\begin{array}{l}\text { Single answer/ } \\
\text { checklist }\end{array}$ & Single practice, group practice, medical care centre, other \\
\hline & $\begin{array}{l}\text { Number of medical assistants and their advanced } \\
\text { qualification }\end{array}$ & Open-ended & Number kind of qualification \\
\hline & Community size & $\begin{array}{l}\text { Single answer/ } \\
\text { scale }\end{array}$ & Between $<5000$ and $>100000$ inhabitants \\
\hline & Number of patients/quarter & Open-ended & Number \\
\hline & Number of home visits/week & Open-ended & Number \\
\hline & Proportion of patients $>65$ years & Open-ended & Number \\
\hline & Number of nursing home patients/quarter & Open-ended & Number \\
\hline
\end{tabular}




\begin{tabular}{|c|c|c|c|}
\hline Topics & Items & Item structure & Response options \\
\hline \multirow[t]{2}{*}{$\begin{array}{l}\text { Organisational } \\
\text { characteristics of the home } \\
\text { visits }\end{array}$} & $\begin{array}{l}\text { Delegation of home visits to whom } \\
\text { Organisational rules (eg, fixed days for home } \\
\text { visits, collection of requests, visit after each } \\
\text { request) }\end{array}$ & $\begin{array}{l}\text { Multiple choice } \\
\text { Multiple choice }\end{array}$ & $\begin{array}{l}\text { Medical assistants with or without qualification, physician assistants, nurses, } \\
\text { care service, others } \\
\text { Fixed days between Monday-Sunday, fixed times between morning-evening, } \\
\text { for request, determine particular date after collection of daily requests, others }\end{array}$ \\
\hline & \multicolumn{3}{|c|}{ Questionnaire for medical assistants/nurses } \\
\hline \multirow{8}{*}{$\begin{array}{l}\text { Demographic characteristics } \\
\text { of medical assistant } \\
\text { Professional characteristics } \\
\text { of medical assistant }\end{array}$} & Age & Open-ended & Year of birth \\
\hline & Gender & Single answer & Female/male \\
\hline & Highest education level & $\begin{array}{l}\text { Single answer/ } \\
\text { checklist }\end{array}$ & Secondary school to university of applied sciences \\
\hline & Vocational qualification & Multiple choice & $\begin{array}{l}\text { Medical assistant, nurse, medical technical assistant, no vocational } \\
\text { qualification, other }\end{array}$ \\
\hline & $\begin{array}{l}\text { Advanced/further education; additional } \\
\text { qualification }\end{array}$ & Multiple choice & $\begin{array}{l}\text { Chronic care manager, advanced primary care assistants VERAH or AGnES, } \\
\text { other }\end{array}$ \\
\hline & Years of professional experience & Open-ended & Number \\
\hline & $\begin{array}{l}\text { YEARS of employment in the current family } \\
\text { practice }\end{array}$ & Open-ended & Number \\
\hline & Regular working hours/week & Open-ended & Number \\
\hline \multirow[t]{5}{*}{$\begin{array}{l}\text { Characteristics of the family } \\
\text { practice }\end{array}$} & Kind of practice/staff composition & $\begin{array}{l}\text { Single answer/ } \\
\text { checklist }\end{array}$ & Single practice, group practice, medical care centre, other \\
\hline & Number of patients/quarter & Open-ended & Number \\
\hline & Community size & $\begin{array}{l}\text { Single answer/ } \\
\text { scale }\end{array}$ & Between $<5000$ and $>100000$ inhabitants \\
\hline & Existing quality management & $\begin{array}{l}\text { Single answer/ } \\
\text { checklist }\end{array}$ & Yes, no, don't know \\
\hline & Number of team meetings/past 12 months & Open-ended & Number \\
\hline \multirow{2}{*}{$\begin{array}{l}\text { Characteristics of delegated } \\
\text { home visits }\end{array}$} & Three essential tasks within home visits & Open-ended & - \\
\hline & Duration of the home visit in average & Open-ended & In minutes \\
\hline
\end{tabular}


participated in our study, the representativeness of the study cohort has to be checked. If biases are visible, data analysis should be adjusted to the main population. Initially, allocation of randomised weeks was planned however problems were encountered during the implementation. Owing to several reasons, alternative time schedules (data collection weeks) were allocated through personal consultation to approximately a quarter (intermediate status after 8 of 12 study months) of FPs. Comparing data from randomised and personalised allocation will be essential to check allocationbased biases.

Furthermore, in our questionnaire we use free text items to collect information about chronic conditions, reasons and results for encounter. Comparison with results of other studies based on secondary analysis of billing data may be limited, since the FPs of our study may document diseases as chronic diagnoses that are relevant for their diagnostic/therapeutic procedures. In contrast, billing data could be influenced by FPs' financial interests resulting in overestimation or underestimation of several diagnoses.

Acknowledgements The authors thank the Saxonian Association of General Practice (SGAM) for supporting this study. The authors also thank the family physicians and their medical assistants who consented to participate in this study and documented their home visits.

Contributors KV, SB and AB collectively drafted the study protocol and sought ethical approval. KV and SB are responsible for the management of the study and drafted and developed this article together. RV and ST revised the manuscript of the paper. All authors read and approved the final manuscript.

Funding This study is mainly funded from our own department resources and partially granted by the Saxonian Association of General Practice (SGAM) that is also co-partner of the study.

Competing interests KV, SB, RV and $A B$ are members of the Saxonian Association of General Practice (SGAM) and the German College of General Practitioners and Family Physicians (DEGAM), that advocate for an adequate external representation of research, teaching and practice in general practice.

Ethics approval Ethical Commission of the Technical University of Dresden (EK 350092013) and adheres to the Declaration of Helsinki.

Provenance and peer review Not commissioned; externally peer reviewed.

Open Access This is an Open Access article distributed in accordance with the Creative Commons Attribution Non Commercial (CC BY-NC 4.0) license, which permits others to distribute, remix, adapt, build upon this work noncommercially, and license their derivative works on different terms, provided the original work is properly cited and the use is non-commercial. See: http:// creativecommons.org/licenses/by-nc/4.0/

\section{REFERENCES}

1. Bourgueil $\mathrm{Y}$, Marek A, Mousquès J. Medical group practice in primary care in six European countries, and the Canadian provinces of Ontario and Quebec: what are the lessons for France. QES 2007;127.

2. Delamaire ML, Lafortune G. Nurses in advanced roles. A description and evaluation of experiences in 12 developed countries. OECD Health Working Papers; 2010.

3. Kringos D, Boerma W, Bourgueil Y, et al. The strength of primary care in Europe: an international comparative study. Br J Gen Pract 2013;63:e742-50.

4. Christensen K, Doblhammer G, Rau R, et al. Ageing populations: the challenges ahead. Lancet 2009;374:1196-208.

5. Statistisches Landesamt des Freistaates Sachsen. 5. Regionalisierte Bevölkerungsprognose für den Freistaat Sachsen bis 2025. http:// www.statistik.sachsen.de/bevprog/ (accessed: 11 Mar 2015).

6. Tesch-Römer C, Wurm S. [Living conditions of ageing and old people in Germany]. Bundesgesundheitsblatt Gesundheitsforschung Gesundheitsschutz 2006;49:499-505.

7. Theile G, Kruschinski C, Buck M, et al. Home visits-central to primary care, tradition or an obligation? A qualitative study. BMC Fam Pract 2011;12:24.

8. Aylin P, Majeed FA, Cook DG. Home visiting by general practitioners in England and Wales. BMJ 1996;313:207-10.

9. Snijder EA, Kersting M, Theile G, et al. [Home visits in German general practice: findings from routinely collected computer data of 158,000 patients]. Gesundheitswesen 2007;69:679-85.

10. van den Berg MJ, Cardol M, Bongers FJ, et al. Changing patterns of home visiting in general practice: an analysis of electronic medical records. BMC Fam Pract 2006;7:58.

11. Bölt R, Graf T. 20 Jahre Krankenhausstatistik. Edited by Statistisches Bundesamt. Wirtschaft und Statistik 2/2012.

12. Kalitzkus $V$, Redaèlli $M$, Jansen $P$, et al. [Still Cause for Hope? Insights into Family Practice in Two Rural Areas in Northrhine-Westfalia]. ZFA 2012;88:1.

13. Joyce C, Piterman L. Trends in GP home visits. Aust Fam Physician 2008;37:1039-42.

14. Heymann R, Weitmann $\mathrm{K}$, Weiss $\mathrm{S}$, et al. [Population density, age distribution and urbanisation as factors influencing the frequency of home visits-an analysis for Mecklenburg-West Pomerania]. Gesundheitswesen 2009;71:423-28.

15. Probst JC, Moore CG, Baxley EG, et al. Rural-urban differences in visits to primary care physicians. Fam Med 2002;34:609-15.

16. Sullivan $C O$, Omar RZ, Forrest $C B$, et al. Adjusting for case mix and social class in examining variation in home visits between practices. Fam Pract 2004;21:355-63.

17. Kuhlen R. Einheitlicher Bewertungsmassstab: Zur Abrechnung von Heimbesuchen. Dtsch Arztebl International 2015;112:5.

18. Voigt K, Tache S, Klement A, et al. Gaining information about home visits in primary care: methodological issues from a feasibility study. BMC Fam Pract 2014;15:87. 